\title{
Research Square \\ The Psychological Effect of COVID-19 and Lockdown on the Population: Evidence from Italy
}

Marco Delmastro ( $\square$ m.delmastro@agcom.it)

Autorità per le Garanzie nelle Comunicazioni

Giorgia Zamariola

Alma Mater Studiorum - Università di Bologna

\section{Research Article}

Keywords: COVID-19, Mental health, Depressive symptoms

Posted Date: September 29th, 2020

DOl: https://doi.org/10.21203/rs.3.rs-82494/v1

License: (9) (1) This work is licensed under a Creative Commons Attribution 4.0 International License.

Read Full License

Version of Record: A version of this preprint was published at Scientific Reports on September 29th, 2020.

See the published version at https://doi.org/10.1038/s41598-020-79850-6. 
4

5

6

7

8

9 Napoli

10

11

12

13

14

15

16

17

18

19

20

21

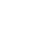

1

2

1

\section{The Psychological Effect of COVID-19 and Lockdown on the \\ Population: Evidence from Italy}

Marco Delmastro ${ }^{\mathrm{a}}$ and Giorgia Zamariola ${ }^{\mathrm{b}}$

a Autorità per le garanzie nelle comunicazioni, Via Isonzo 21/b Roma - Centro Direzionale/Isola B5

b Alma Mater Studiorum - Università di Bologna, Via Zamboni, 33, 40126 Bologna

\section{Corresponding Author:}

Marco Delmastro

m.delmastro@agcom.it

\section{Conflict of interest}

The authors have no conflict of interest to declare. 
 \\ Evidence from Italy}

Abstract

The COVID-19 pandemic and the lockdown measures adopted to prevent the spread of the disease had a huge impact on a personal, social, and economic level for the world population. In Europe, Italy was one of the frontrunner countries dealing with an emergency that significantly affected people's lives. Previous research on the psychological impact of the pandemic revealed an increase in anxiety, depression, and feelings of distress; however, these studies were conducted on nonrepresentative samples of the population reached through social media channels, a method that is likely to lead to many forms of statistical and methodological bias. For the first time to our knowledge, we measured depressive symptoms on 6,700 Italian individuals, representative of the Italian population in terms of age, gender, and geographical areas revealing higher scores of depressive symptoms in females, younger adults, people reporting professional uncertainty and lower socio-economic status. A positive correlation was also found for individuals living alone, those who could not leave home for going to work, and people with a case of COVID-19 in the family, whereas the region of residence was not a significant predictor of depressive symptoms. These findings underline the importance of considering the psychological effects of COVID-19 and providing support to individuals seeking mental health care. 
On 31 December 2019, the World Health Organization (WHO) received information of cases of pneumonia of unknown cause in Wuhan City, China. The cause was identified by Chinese authorities as being a novel coronavirus afterwards named the "COVID-19 virus". Due to the rapid increase in the number of cases outside China, on 11 March 2020, WHO Director-General announced that the outbreak could be characterized as a pandemic.

After China, Italy was the first European country to report a case of death due to COVID-19 dated on 21 February 2020 in Lombardy, followed by a series of outbreaks in the Northern regions and a rapid increase of deaths and cases of infection. In response to this emergency, Italy was the first country in Europe to adopt restrictive physical and social distancing measures to limit the spread of the disease which led to a full lockdown of the entire country from 9 March 2020 until 3 May 2020 (so-called "phase 1"), and other measures, such as the prohibition of individual movements outside people's region of domicile, until 2 June ("phase 2"; for more information see COVID-19 Health System Response Monitor). Since the beginning of the emergency there have been 233,515 confirmed cases of COVID-19 with 33,530 deaths reported (as of 2 June 2020, data retrieved from the Italian Ministry of Health).

The period of lockdown has been characterised by travel restrictions and the mandatory closure of schools, nonessential commercial activities and industries. People were requested to stay at home and socially isolate themselves to prevent the spread. Such an experience has the potential to influence people's mental state evoking fear of contagion, worry about disease and death, in addition to anxiety due to health and economic uncertainties (Asmundson and Taylor, 2020). Severe pandemic lockdowns and quarantine are a further source of distress since individuals are confined, socially isolated, might lose their income, and their activities are restricted (Brooks et al., 2020). This situation is worsened by an "infodemic", i.e., an overabundance of information, some of which can be misleading or even harmful (World Health Organization, 2020).

Recent studies have shown that the COVID-19 pandemic affected the mental health. One recent narrative review (Rajkumar, 2020) comprises 28 articles addressing the issue of mental health revealed the presence of symptoms of anxiety, depression, and self-reported stress associated with disturbed sleep in response to the pandemic. These articles include samples from China, Iran, Canada, Brazil, Singapore, India, and Japan. The results showed that variables such as female gender, being a student, having symptoms suggestive of COVID-19, and poor perceived health were associated with higher rates of anxiety and depression. Other characteristics that contributed to stress and mental morbidity were unpredictability, uncertainty, seriousness of the disease, misinformation, and social isolation. Another review (Kontoangelos et al., 2020) pointed out that maladaptive behaviours, emotional distress, and defensive responses are psychological reactions that can be experienced during a pandemic. More specifically, data reported the prevalence of significant post-traumatic stress symptoms and anxiety. Sibley and colleagues (2020) conducted a pre- and post-lockdown study showing an increase in psychological distress after the lockdown. However, higher levels of sense of community and resilience were also found, providing support to the presence of some positive outcomes related to the challenges faced during the pandemic.

A study on a sample from the Italian population (Rossi et al., 2020) showed high rates of posttraumatic stress symptoms, depression, anxiety, sleep disorders, perceived stress reported during the lockdown, with females expressing higher impact on their mental health. Other risk factors identified were being under quarantine, having a significant one deceased by COVID-19, working 
discontinuity, or experiencing other stressful events (i.e. working, financial, relationship or housing problems) linked to the pandemic or lockdown measures.

Another study by Casagrande and colleagues (2020) showed a relationship between COVID-19 spread and feelings of anxiety, depression, distress, sleep disorders and post-traumatic stress disorders. A similar research (Forte et al., 2020) revealed that being of younger age, student, female, and having had a direct contact with COVID-19 infection were associated with a greater psychological impact on psychopathological dimensions such as anxiety, distress, and sleep disturbance. Mazza and colleagues (2020) found that female gender, negative affect, and detachment were related to higher levels of psychological distress. Higher depression and stress levels were found in people with an acquaintance infected with COVID-19 and in individuals with a history of stressful situations and medical problems. Other factors affecting anxiety and stress levels were having a family member infected with COVID-19, being young in age and needing to leave one's domicile to go to work.

Additional research identified moderating variables that have an impact on reported mental health during the lockdown (Pakenham et al., 2020). This study included a measure of psychological flexibility described as the ability to adapt to changing situation with a resilient attitude. The results of the survey revealed that psychological flexibility is a protective factor which helps to mitigate the negative effects of the pandemic and lockdown, such as depression, anxiety, and distress.

To our knowledge, this is the first study conducted on a representative sample of the Italian population exploring the psychological effects of COVID-19 pandemic and lockdown. Previous research adopted a convenient sampling strategy administering the questionnaire through social media channels and snowball technique which is likely to lead to recruitment bias (i.e. sample selection, hence biases in statistical results).

The aim of the present research was to explore the effects of COVID-19 on mental health, focusing on depressive symptoms. To this end, the Short Mood and Feelings Questionnaire (SMFQ) was administered to a representative sample of the Italian population. Given the sample age range (16$65+$ ), the SMFQ was chosen for its simplicity and ease of understanding. The study was conducted right after the lockdown phase, in June 2020, in order to collect the immediate reactions to the emergency. Socio-demographics were also collected to analyse which kind of moderators might represent risk or protective factors for mental health symptoms. Socio-demographics variables included age, gender, education, and socio-economic status. Information on profession and household (living alone or not) and working (still going out to reach workplace or not) conditions were also gathered. Lastly, questions on the municipality of residence and the presence of a case of COVID-19 in the family were included.

\section{Method}

To evaluate the effect of the pandemic on mood and feelings of the Italian population a psychometric approach was adopted. Due to the special nature of the period which prevented to conduct experimental studies meeting participants face-to-face, a psychometric self-reporting methodology was chosen. We adopted the short version of the Mood and Feelings Questionnaire (SMFQ; Messer et al., 1995) which includes 13 items indicating how much individuals have felt or acted depressed during the last few weeks (e.g., "I felt miserable or unhappy", "I didn't enjoy anything at all"). The answers are given on a three-point scale where respondents are asked to decide if the statements are "true", "sometimes true", or "not true". Scoring of the SMFQ is 
obtained by summing together the point values of responses for each item. The response choices and their designated point values are as follows: "not true" $=0$ points, "sometimes true" $=1$ point, "true" = 2 points. Higher scores on the SMFQ indicate more severe depressive symptoms. The range of scores on the SMFQ varies from 0 to 26. A score of 12 or higher may indicate the presence of depression in the respondent (see among others Thabrew et al., 2018). As reported by Jarbin et al. (2020) suggested cut-offs on the SMFQ self-report have been divergent with cut-offs ranging from 4-5 in studies with just fair AUC and younger subjects to a high of 10-12 in studies with good AUCs and older subjects.

The SMFQ has been validated with children and young people aged between 6 and 19, however a study by Turner et al. (2014) showed that it is a useful and valid diagnostic tool for studying depression within a community-based sample in late adolescence and that it relates well to an adult measure of depression, namely the Clinical Interview Schedule-Revised form (CIS-R; Lewis et al., 1992). The SMFQ has a number of important (psychometric and implementation) features (i.e. internal consistency, test-retest reliability, validity, sensitivity to change as to the former, and brevity, availability, ease of scoring as to the latter), thus making it a useful tool for analysing mood and feelings attitude, especially during a pandemic when other methodologies such as experimental lab studies present severe and objective constraints.

In this work, we focused on young adults (16-24) and adults (25+) so as to proceed with a selfadministered questionnaire that was completed by the sampled respondents ${ }^{1}$. The final sample was composed of 6,692 Italian individuals, representative of the Italian population in terms of age, gender, and geographical area. More specifically, the sample design and the stratification were based on the following variables: i) age (7 age groups: $16-17 ; 18-24 ; 25-34 ; 35-44 ; 45-54 ; 55-64$ : $65+)$; iii) gender, iii) geographical breakdown (all Italian regions and size of the residential community; 7 classes), iv) education (2 classes: graduates and non-graduates). The field data collection was conducted in June 2020 (from the $4^{\text {th }}$ of June to the $19^{\text {th }}$ of June) with a mixed technique CATI (Computer Assisted Telephone Interviewing) and CAWI, (Computer Assisted Web Interviewing) as to limit any risks in terms of sample's distortion and self-selection.

All methods were carried out in accordance with the Declaration of Helsinki. The experiment was approved by Autorità per le Garanzie nelle Comunicazioni. Informed consent was obtained from all participants and from a parent and/or legal guardian for participants under 18.

Since the SMFQ has mainly been validated for children and young adults (Turner et al., 2014), in our analysis we separated young adults (aged between 16-24) from adults (25+). Table 1 illustrates the age distribution (weighted and not weighted) of our sample and offers a comparison with the Italian population, showing very similar values.

As a preliminary remark regarding data consistency, it should be noted that Cronbach's alpha - i.e., a measure of the reliability of the questionnaire - is equal to 0.91 for the overall sample, 0.90 for the young adult group and 0.91 for the adult group, where alpha 0.90 or above is considered excellent for internal consistency reliability of the SMFQ (Jarbin et al., 2020; see also Thabrew et al., 2018). We added to these variables official COVID-19 statistics in order to disentangle the role played by the spatial variability of the pandemic diffusion on individual mood. We used the official data released every day at 6 PM (UTC $+1 \mathrm{~h}$ ) by the "Dipartimento della Protezione Civile" (the National Department of Civil Protection of the Presidency of the Council of Ministers) and archived

\footnotetext{
${ }^{1}$ Younger individuals would have needed the direct assistance of their parents, making the filling in of the questionnaire very cumbersome.
} 
on GitHub (see https://github.com/pcm-dpc/COVID-19). At times, data may just be a proxy of the actual state variables. In particular, the number of confirmed COVID-19 cases (i.e. new COVID-19 positives and total COVID-19 positives) depends on the effort being devoted to finding new positive cases. In addition, deaths statistics for Italy include coronavirus victims who died either in hospital or outside and were tested before or after dying. Regardless of their goodness and accuracy, these statistics are those that have been most widely disseminated by health institutions and the news outlets, thus potentially influencing the mood and feelings of Italian citizens.

\section{Results}

The first step was to analyse the distribution of the SMFQ score among Italian population, just after the lockdown period, i.e., at June 2020 (see Figure 1). As we would expect, the total distribution of SMFQ score is asymmetric and skewed to the right (also by a skewness test), with mean at 5.2. It presents a mode near 0 , and a slight bump around 12. If we define a cut-off at 12 that may indicate the presence of depression in the respondent (see Thabrew et al., 2018), then, at June 2020, 14.4\% of the Italian population lied above this threshold. In Figure 2, we compare the score distribution of the two age groups: young adults (16-24) vs. adults (25+). Both distributions follow a similar pattern (skew to the right with a mode near 0 and a long tail thereafter), however the scores across groups age do not have the same distribution function ${ }^{2}$. In particular, the mean score of the two groups is significantly different (7.04 for young adults and 4.97 for adults), and the probability of scoring a higher value than the cut-off (SMFQ $\geq 12$ ) is significantly higher for the youngest (24.17\% vs. $13.33 \%$; Table 2$)$.

The second step was to run econometric analysis on the overall population, correlating the SMFQ score to some major determinants. Following the existing literature (see above), we included sociodemographic (age and gender), economic (unemployed, lay-off and poor) and context (living alone, size of the municipality of residence) variables. Their operative description and summary statistics are reported in Tables 3 and 4. Given the characteristic of the dependent variable (i.e. the SMFQ score, which is an integer which lies between 0 and 26) a (Poisson) count model with double censoring (left at 0 and right at 26) has been estimated ${ }^{3}$. Model (1) in Table 5 shows results of the count model with aforementioned "traditional" explanatory variables. Younger individuals are confirmed to be more exposed to depressive mood (the coefficient of age is negative and significant at 99\%), as well as women (coefficient .212 and std. dev. .0286). This means that younger adults and women are more vulnerable when it comes to the onset of depressive symptoms in response to the pandemic. A negative economic condition significantly affects depression in terms of future prospect (unemployed: .152 and std. dev. .0497), absolute value (poor: .217 and std. dev. .0394) and, above all, professional uncertainty (lay-off: .482 and std. dev. .0658) ${ }^{4}$. This result stresses the importance of considering also economic vulnerability which the pandemic and lockdown affected impacting people of lower socio-economic status. Loneliness is also significantly correlated with higher values of SMFQ, both in terms of family nucleus (i.e., living alone: .166 and std. dev. .0398) and social context (i.e. size of the municipality of residence ${ }^{5}:-.0235$ and std. dev. .0071). The

\footnotetext{
${ }^{2}$ Nonparametric statistical tests (i.e. Kolgomorov-Smirnov test, Wilcoxon rank-sum test and Epps-Singleton test) confirm that the two samples are not drawn from the same distribution function. For this reason, the econometric analysis is also run for the two age groups separately (see Table 6).

${ }^{3}$ In the Appendix (Table A.1), we present also results of linear models.

${ }^{4}$ Significantly, uncertainty displays (by t-tests) a significantly higher effect than a negative economic status.

${ }^{5}$ Note that this variable is (negative and) significant in a logarithmic but not in a linear form, meaning that living in small and very small towns mostly influences (positively) the probability of scoring a high value of SMSQ.
} 
lockdown aggravated the condition of people living alone removing their opportunities to gather with closed ones and limiting the moments of social exchange and sharing which resulted in developing depressive symptoms.

We then turned to the core of the analysis, by adding variables related to the pandemic phase into two stages. First, we added variables concerning the experience of the individual during the pandemic (see model 2 of Table 5). COVID-19 is a dummy variable which is equal to 1 when the individual or someone in her/his family tested positive to coronavirus, 0 otherwise ${ }^{6}$. Moreover, we looked at the effect of lockdown introducing a dummy variable that is equal to 1 whenever the individual kept on going to the workplace during the lockdown period and is 0 in the opposite situation of people staying at home ${ }^{7}$. Results of model 2 show that COVID-19 is the variable that displays the greatest effect on the probability of falling into depression (.733 and std. dev. .0562). To obtain a more analytical account of this effect, we calculated a probit model of scoring more than the cut-off (SMQF $\geq 12$; see Table A.2) and then plot the probability of depression as a function of age and COVID-19 (Figure 3.a). The effect of this latter variable is huge and mostly doubles the probability of depression at any age. Having experienced the virus within the family clearly makes the pandemic more vivid, it increases risk perception, generating worry for the loved one and for themselves which in turn affects mental health. Also, the fact of having experienced a complete lockdown shows a clear effect on depressive symptoms (the coefficient of "no lockdown" is equal to -.123 with std. dev. .0551). However, the amplitude of this effect (and that of other variables) is of a different (much smaller) order, ranging between 1-3\% (see Figure $3 b)^{8}$.

In the third step (models 3-6 of Table 5), we introduced variables related to the diffusion of the COVID-19 pandemic in the local area of residence of Italian citizens (either the county or the region) ${ }^{9}$. In particular, we used the number of confirmed cases (at county level) and deaths (at a regional level) in June 2020, in terms of absolute and relative (as a \% of local population) values. Indeed, these statistics were the most used by media outlets and public institutions to inform Italian citizens about the spread of the pandemic ${ }^{10}$. Results of models 3-6 of Table 5 confirm previous effects and show, interestingly, that the local diffusion of the pandemic does not affect the probability of scoring high values of SMFQ. This result is in line with previous results that investigated the dynamic evolution of TV viewership of Italian national and local news and showed that the attention of individuals to the pandemic is not related to the local spread but to the national diffusion (Castriota, Delmastro and Tonin, 2020). In sum, results show that anxiety and depressive

\footnotetext{
${ }^{6}$ From our data, $7.6 \%$ of Italian population has experienced directly or indirectly negative health effects from coronavirus (see Table 3). This value seems to be coherent with official statistics. In fact, at June 2020, confirmed cases are nearly $0.5 \%$ of Italian population. This value must be times a factor of 7.3 if one considers only the close family network (see Istat, 2018). When one takes into account also the largest family network (second- and third-degree family members), one may reach percentages around $7-8 \%$ of Italian population.

${ }^{7}$ Of course, by comparing scores of individuals who experienced total lockdown with people that were forced to keep going to their workplace we greatly underestimate the effect of lockdown. Indeed, the second category of individuals suffered severe stress and anxiety from the particular situation and type of job they did (by definition public interest work in hospitals, supermarkets, pharmacies,...), so that are not able to compare lockdown with a "normal" situation. ${ }^{8}$ However, as mentioned (see previous footnote), the coefficient of the variable "no lockdown" underestimates the effect of lockdown. Indeed, this result tells us that individuals who were forced to go to the workplace during this period and, presumably, suffered from stress and anxiety due to the situation and type of work they did, score significantly lower values of SMFQ than people under lockdown. Therefore, the effect of lockdown on depression may be significantly higher than that detected.

${ }^{9}$ At county level, the only available official statistics related to the number of COVID-19 confirmed cases. At regional level, there are other statistics such as the number of deaths and recovered individuals.

${ }^{10}$ In any case, the use of other local variables on the pandemic (recovered, intensive care, ...) confirms results of Table 5 .
} 
symptoms are not connected with the local spread of the virus (but only with family cases), since they are widespread nationwide (and this may also be the effect of a national lockdown).

As a final step, we split the sample into two age groups (young adults and adults) and we ran count statistical models for the two groups, separately (see the Appendix for linear models, Table A.3). Results are reported in Table $6^{11}$ (in column 1 we report results for all individuals - as in model 2 of Table 5 -, in column 2 those of young adults and in column 3 those of adults) and confirm previous outcomes for both age groups, in particular with regard to the significance and size of the effect of COVID-19 (whose coefficient is equal to .485 - std. dev. .087 - for young adults and to .77 - std. dev. .0619). There are, however, three interesting and significative differences regarding younger individuals: 1) family wealth does not significantly affect depressive mood of the youngest people, 2) the social context in terms of the size of the municipality where individuals live comes out to be less important for the youngest, and 3) age seems to display a U-inverted relation with depression score. Indeed, this relation is positive for young people (.101 and std. dev. .0143) and negative for older individuals (-.00954 and std. dev. .0013).

\section{Discussion}

To our knowledge, this is the first study exploring the effects of COVID-19 on mental health in a large and representative sample of the Italian population. Our results show higher scores of depressive symptoms in females, younger adults, people reporting professional uncertainty and lower socio-economic status. A positive correlation was also found for individuals living alone, those who could not leave home for going to work, and people with a case of COVID-19 in the family. Interestingly, the region of residence was not a significant predictor of depressive symptoms.

Our findings highlight that the effect on mental health is related more broadly to the lockdown condition rather than the actual number of reported cases of deaths and infected (which were higher in the northern regions). The Short Mood and Feelings Questionnaire proved to be a reliable measure of depressive symptoms for both young and older adults, as shown by the separate analyses for age ranges 16-24 and 25+. The strength of the questionnaire lies in its easiness of administration and understanding, essential characteristics for detecting mental health's effects during such an unprecedented situation.

Our research provides support to previous studies and extends the understanding of the psychological impact of the lockdown using a more reliable and scientifically sound method for sample's selection. In line with our findings, previous studies on the psychological effects of COVID-19 also found that females are more affected by depression, anxiety, and distress (Rossi et al., 2020; Casagrande et al., 2020; Mazza et al., 2020). Additionally, a recent review of the literature (Salk et al., 2017) revealed that females are more likely to report depressive symptoms and to receive a diagnosis of depression.

The higher vulnerability of younger adults was observed in previous research as well in relation to anxiety and distress (Forte et al., 2020; Mazza et al., 2020). Our results complement this picture and reveal an association with depressive symptoms. This result is of high importance when thinking

\footnotetext{
${ }^{11}$ Some variables (the professional ones - Unemployed, Lay-off and No lockdown - and Living alone) are not introduced in the model of younger individuals because they do not apply to them (or apply only to a very small part of them).
} 
about policy and health measures to be adopted to help younger generations to overcome the individual and social loss that they experienced during the pandemic.

Regarding work and financial conditions, our results confirm that professional uncertainty and low socio-economic status are related to depression, as found by Rossi and colleagues (2020) for people with working discontinuity and financial struggles.

On the topic of household conditions, our findings highlight the role played by living alone in the experience of depressive symptoms. Despite new technologies aided in feeling closer to significant ones even from distance, the lack of social relations and daily gatherings significantly affected people's mood. It is also worth noting that older individuals living by themselves could have been less familiar with the potential of new technologies, therefore limiting their chance to engage in virtual exchanges with loved ones.

Importantly, while previous studies revealed higher anxiety for individuals leaving their home to go to work (Rossi et al., 2020; Mazza et al., 2020), our research found lower depression in those people who kept going physically to the workplace. This finding shows that, even if going out triggered anxiety and fear of getting infected, keeping a working routine helped to feel less depressed and lonely.

Lastly, as previous research has shown (Rossi et al., 2020; Forte et al., 2020; Mazza et al., 2020), having a case of COVID-19 in the family had an impact on reported depression. This negative experience could amplify the feelings of fear, anxiety, stress and enhance the perceived risk on the probability of infection and the potentially fatal consequences derived from catching the virus.

It is crucial to remark that, other things being equal (in particular, the eventual presence of a COVID-19 case in the family), no differences were found in relation to the region of residence, while Forte et al. (2020) and Casagrande et al. (2020) found more sleep disturbances and state of anxiety in Northern Italy. Our study, which is statistically grounded, reveals that feelings of anxiety and depression were spread in the whole country ${ }^{12}$.

As highlighted by Holmes et al. (2020), it is likely that the prevalence of clinically relevant numbers of people with anxiety, depression, and engaging in harmful behaviours (such as suicide and selfharm) will increase. The potential consequences of an economic recession on mental health may be acute on people directly affected by COVID-19 and their caregivers. Data on the severe acute respiratory syndrome epidemic in 2003 reported a 30\% increase in suicide in those aged 65 years and older; around $50 \%$ of recovered patients remained anxious; and $29 \%$ of health-care workers experienced probable emotional distress. Post-traumatic stress disorder and depression were also reported among patients who survived severe and life-threatening illness (Holmes et al., 2020).

\section{Conclusions and Future Work}

The present research stresses the need to take into account the psychological consequences of the COVID-19 pandemic and lockdown, aiming at the implementation of a holistic approach that considers both physical and mental health and well-being. The society as a whole, and in particular vulnerable groups such as children, older adults, people with existing mental health disorders, and

\footnotetext{
${ }^{12}$ This effect is clearly linked to the very nature of the phenomenon under investigation (i.e. a pandemic) that can potentially spread everywhere and is therefore likely to generate anxiety and depression even in places where it has not yet arrived (or will never arrive).
} 
320 front-line health-care workers, call for support to overcome this difficult time. Next months will be 321 characterised by uncertainty, financial insecurity and worry, therefore it is pivotal to provide help through mental health care which could also make use of the Telemedicine, e.g., telehealth and app tools (see Kontoangelos et al., 2020). Indeed, online interactions can promote a sense of connection and improve psychological well-being, as highlighted by Van Bavel and colleagues (2020).

325 Future studies should consider the long-term effects of the pandemic on mental health, adopting a 326 longitudinal design to measure change over time. Additional work should aim at comparing the 327 experiences of the different countries affected by the pandemic in order to understand the size of the psychological impact and the potential risk and protective factors. Importantly, the data on people who seek for mental health assistance should closely monitored to prevent a second pandemic of 330 psychological distress. 


\section{References}

Asmundson GJ, Taylor S. How health anxiety influences responses to viral outbreaks like COVID19: What all decision-makers, health authorities, and health care professionals need to know. Journal of Anxiety Disorders. 2020 Apr;71:102211.

Brooks SK, Webster RK, Smith LE, Woodland L, Wessely S, Greenberg N, Rubin GJ. The psychological impact of quarantine and how to reduce it: rapid review of the evidence. The Lancet. 2020 Feb 26.

Rajkumar RP. COVID-19 and mental health: A review of the existing literature. Asian journal of psychiatry. 2020 Apr 10:102066.

Kontoangelos K, Economou M, Papageorgiou C. Mental health effects of COVID-19 pandemia: a review of clinical and psychological traits. Psychiatry investigation. 2020 Jun;17(6):491.

Sibley CG, Greaves LM, Satherley N, Wilson MS, Overall NC, Lee CH, Milojev P, Bulbulia J, Osborne D, Milfont TL, Houkamau CA. Effects of the COVID-19 pandemic and nationwide lockdown on trust, attitudes toward government, and well-being. American Psychologist. 2020 Jun 4.

Rossi R, Socci V, Talevi D, Mensi S, Niolu C, Pacitti F, Di Marco A, Rossi A, Siracusano A, Di Lorenzo G. COVID-19 pandemic and lockdown measures impact on mental health among the general population in Italy. An N = 18147 web-based survey. medRxiv. 2020 Jan 1.

Casagrande M, Favieri F, Tambelli R, Forte G. The enemy who sealed the world: Effects quarantine due to the COVID-19 on sleep quality, anxiety, and psychological distress in the Italian population. Sleep Medicine. 2020 May 12.

Castriota S., Delmastro M., Tonin, M. The demand for news in Italy during COVID-19, mimeo, August 2020.

Forte G, Favieri F, Tambelli R, Casagrande M. The Enemy Which Sealed the World: Effects of COVID-19 Diffusion on the Psychological State of the Italian Population. Journal of Clinical Medicine. 2020 Jun;9(6):1802.

Jarbin H, Ivarsson T, Andersson M, Bergman H, Skarphedinsson G. Screening efficiency of the Mood and Feelings Questionnaire (MFQ) and Short Mood and Feelings Questionnaire (SMFQ) in Swedish help seeking outpatients. PLOS ONE. 2020 March; 15(3).

Mazza C, Ricci E, Biondi S, Colasanti M, Ferracuti S, Napoli C, Roma P. A nationwide survey of psychological distress among Italian people during the COVID-19 pandemic: Immediate psychological responses and associated factors. International Journal of Environmental Research and Public Health. 2020 Jan;17(9):3165.

Pakenham KI, Landi G, Boccolini G, Furlani A, Grandi S, Tossani E. The Moderating Roles of Psychological Flexibility and Inflexibility on the Mental Health Impacts of COVID-19 Pandemic and Lockdown in Italy. Journal of Contextual Behavioral Science. 2020 Jul 20.

Messer SC, Angold A, Costello EJ, Loeber R, Van Kammen W, Stouthamer-Loeber M. Development of a short questionnaire for use in epidemiological studies of depression in children and adolescents: Factor composition and structure across development. International journal of methods in psychiatric research. 1995 Dec 1;5:251-62. 
373 Turner N, Joinson C, Peters TJ, Wiles N, Lewis G. Validity of the Short Mood and Feelings

374 Questionnaire in late adolescence. Psychological assessment. 2014 Sep;26(3):752.

375 Lewis G, Pelosi AJ, Araya R, Dunn G. Measuring psychiatric disorder in the community: a

376 standardized assessment for use by lay interviewers. Psychological medicine. 1992 May;22(2):465-

37786.

378 Salk RH, Hyde JS, Abramson LY. Gender differences in depression in representative national 379 samples: meta-analyses of diagnoses and symptoms. Psychological bulletin. 2017 Aug;143(8):783.

380 Thabrew H, Stasiak K, Bavin L, Frampton C, Merry S. Validation of the Mood and Feelings 381 Questionnaire (MFQ) and Short Mood and Feelings Questionnaire (SMFQ) in New Zealand help382 seeking adolescents, Int J Methods Psychiatr Res. 2018; 27:e1610.

383 Jarbin H, Ivarsson T, Andersson M, Bergman H, Skarphedinsson G. Screening efficiency of the 384 Mood and Feelings Questionnaire (MFQ) and Short Mood and Feelings Questionnaire (SMFQ) in 385 Swedish help seeking outpatients. PloS one. 2020 Mar 25;15(3):e0230623.

386 Holmes EA, O'Connor RC, Perry VH, Tracey I, Wessely S, Arseneault L, Ballard C, Christensen H, 387 Silver RC, Everall I, Ford T. Multidisciplinary research priorities for the COVID-19 pandemic: a 388 call for action for mental health science. The Lancet Psychiatry. 2020 Apr 15.

389 Van Bavel JJ, Baicker K, Boggio PS, Capraro V, Cichocka A, Cikara M, Crockett MJ, Crum AJ, 390 Douglas KM, Druckman JN, Drury J. Using social and behavioural science to support COVID-19 391 pandemic response. Nature Human Behaviour. 2020 Apr 30:1-2.

392 COVID-19 Health System Response Monitor - Italy. Available online:

393 www.COVID19healthsystem.org/countries/italy

394 World Health Organization. Coronavirus Disease (COVID-2019) Situation Reports. Available 395 online: https://www.who.int/docs/default-source/coronaviruse/situation-reports/20200202-sitrep-13396 ncov-v3.pdf?sfvrsn=195f4010_6 
Table 1: Population: sample (weighted and not weighted) vs. Italian population

\begin{tabular}{|c|c|c|c|}
\hline & \multicolumn{2}{|c|}{ Sample population } & \multirow{2}{*}{$\begin{array}{l}\text { Italian population } \\
\%\end{array}$} \\
\hline & N. & $\%$ (weighted) & \\
\hline Total $(16+)$ & 6,692 & $100.0 \%$ & $100.0 \%$ \\
\hline Young adults (16-24) & 666 & $10.0 \%(10.3 \%)$ & $10.2 \%$ \\
\hline Adults $(25+)$ & 6,026 & $90.0 \%(89.7 \%)$ & $89.8 \%$ \\
\hline
\end{tabular}

Table 2: (S)MFQ score for sample population, and by age groups (weighted and not weighted)

\begin{tabular}{lllll}
\hline Population & Average (weighted) & $\mathbf{\%} \geq \mathbf{1 2}$ (cut-off) (weighted) & Minimum & Maximum \\
\hline Total & $5.18(5.21)$ & $14.41(14.83)$ & 0 & 26 \\
\hline Young adults (16-24) & $7.04(7.08)$ & $24.17(24.91)$ & 0 & 26 \\
\hline Adults (25+) & $4.97(5.00)$ & $13.33(13.68)$ & 0 & 26 \\
\hline
\end{tabular}

405

Table 3: Summary statistics of independent variables (weighted and not weighted)

\begin{tabular}{|c|c|c|c|c|c|c|}
\hline Variable & Description & N. & Avg. (weighted) & Std. dv. & Minimum & Maximum \\
\hline Gender (female) & 1 if female; 0 otherwise & 6,692 & $.524(.517)$ & .499 & 0 & 1 \\
\hline Age & Age (number of years) & 6,692 & $50.489(50.323)$ & 17.928 & 16 & 96 \\
\hline Unemployed & 1 if unemployed; 0 oth. & 6,692 & $.066(.076)$ & .249 & 0 & 1 \\
\hline Lay-off & 1 if a lay-off; 0 otherwise & 6,692 & $.025(.029)$ & .155 & 0 & 1 \\
\hline Poor & 1 if poor $^{(*)} ; 0$ otherwise & 6,692 & $.110(.123)$ & .313 & 0 & 1 \\
\hline Living alone & $\begin{array}{l}1 \text { if she/he lives alone; } 0 \\
\text { otherwise }\end{array}$ & 6,692 & $.154(.149)$ & .360 & 0 & 1 \\
\hline COVID-19 & $\begin{array}{l}1 \text { if a COVID-19 case in } \\
\text { her/his family; } 0 \text { otherwise }\end{array}$ & 6,643 & $.076(.076)$ & .265 & 0 & 1 \\
\hline No lockdown & $\begin{array}{l}1 \text { if he/she has kept working } \\
\text { from workplace (during } \\
\text { lockdown); } 0 \text { if she/he } \\
\text { experienced home } \\
\text { lockdown }\end{array}$ & 6,643 & $.102(.109)$ & .302 & 0 & 1 \\
\hline
\end{tabular}

(*) "Poor" is defined from a 5-point Likert scale as the worst economic condition, in which the individual experiences severe economic difficulties, lacking sufficient money to live at a normal standard (in 2019, the Italian Statistical Office has estimated that $7.7 \%$ of Italian individuals could be regarded as poor; however, this values has sharply increased in 2020 due to the economic crisis related to the COVID-19 pandemic).

Table 4: Summary statistics of geographical variables (at the $31^{\text {st }}$ of May 2020)

\begin{tabular}{lllll}
\hline Variable & N. & Average & Minimum & Maximum \\
\hline Population of the municipality of residence ${ }^{(*)}$ & 2,172 & 19,715 & 100 & $2,761,477$ \\
\hline Population of the county of residence & 110 & 550,048 & 56,938 & $4,300,000$ \\
\hline Population of the region of residence & 20 & $3,013,808$ & 125,666 & $1.00 \mathrm{e}+07$ \\
\hline Number of COVID-19 cases (county) & 110 & 2,088 & 22 & 23,076 \\
\hline Number of COVID-19 deaths (region) & 20 & 1,671 & 22 & 16,112 \\
\hline
\end{tabular}

\footnotetext{
${ }^{(*)}$ In Italy there are 7,982 municipalities; sample individuals live in 2,172 of them.
}

Sources: Italian Statistical Office (ISTAT) and Italian Ministry of Health 
Table 5: Result of econometric models on the (S)MFQ score

\begin{tabular}{|c|c|c|c|c|c|c|}
\hline VARIABLES & $\begin{array}{c}(1) \\
\text { regr_1 } \\
\text { mfq }\end{array}$ & $\begin{array}{c}(2) \\
\text { regr_2 } \\
\text { mfq }\end{array}$ & $\begin{array}{c}\text { (3) } \\
\text { regr_3 } \\
\text { mfq }\end{array}$ & $\begin{array}{c}(4) \\
\text { regr_4 } \\
\text { mfq }\end{array}$ & $\begin{array}{c}(5) \\
\text { regr_5 } \\
\text { mfq }\end{array}$ & $\begin{array}{c}\text { (6) } \\
\text { regr_6 } \\
\text { Mfq }\end{array}$ \\
\hline Gender (female) & $\begin{array}{c}0.212 * * * \\
(0.0286)\end{array}$ & $\begin{array}{c}0.238 * * * \\
(0.0302)\end{array}$ & $\begin{array}{c}0.238 * * * \\
(0.0303)\end{array}$ & $\begin{array}{c}0.240 * * * \\
(0.0297)\end{array}$ & $\begin{array}{c}0.239 * * * \\
(0.0299)\end{array}$ & $\begin{array}{c}0.240 * * * \\
(0.0298)\end{array}$ \\
\hline Age & $\begin{array}{l}-0.0108 * * * \\
(0.000828)\end{array}$ & $\begin{array}{c}-0.00985^{* * *} \\
(0.000838)\end{array}$ & $\begin{array}{c}-0.00986 * * * \\
(0.000839)\end{array}$ & $\begin{array}{c}-0.00984 * * * \\
(0.000839)\end{array}$ & $\begin{array}{c}-0.00985^{* * *} \\
(0.000839)\end{array}$ & $\begin{array}{c}-0.00983 * * * \\
(0.000839)\end{array}$ \\
\hline Unemployed & $\begin{array}{c}0.152 * * * \\
(0.0497)\end{array}$ & $\begin{array}{c}0.133 * * * \\
(0.0503)\end{array}$ & $\begin{array}{c}0.133 * * * \\
(0.0505)\end{array}$ & $\begin{array}{l}0.126^{* *} \\
(0.0496)\end{array}$ & $\begin{array}{l}0.128 * * \\
(0.0500)\end{array}$ & $\begin{array}{l}0.127 * * \\
(0.0498)\end{array}$ \\
\hline Lay-off & $\begin{array}{c}0.481 * * * \\
(0.0658)\end{array}$ & $\begin{array}{c}0.316^{* * * *} \\
(0.0802)\end{array}$ & $\begin{array}{c}0.316^{* * * *} \\
(0.0805)\end{array}$ & $\begin{array}{l}0.321 * * * \\
(0.0845)\end{array}$ & $\begin{array}{c}0.315^{* * * *} \\
(0.0823)\end{array}$ & $\begin{array}{l}0.319 * * * \\
(0.0844)\end{array}$ \\
\hline Poor & $\begin{array}{c}0.217 * * * \\
(0.0394)\end{array}$ & $\begin{array}{c}0.219 * * * \\
(0.0425)\end{array}$ & $\begin{array}{c}0.218 * * * \\
(0.0426)\end{array}$ & $\begin{array}{c}0.213 * * * \\
(0.0431)\end{array}$ & $\begin{array}{c}0.216 * * * \\
(0.0427)\end{array}$ & $\begin{array}{c}0.215 * * * \\
(0.0430)\end{array}$ \\
\hline Living alone & $\begin{array}{c}0.166 * * * \\
(0.0398)\end{array}$ & $\begin{array}{c}0.192 * * * \\
(0.0409)\end{array}$ & $\begin{array}{c}0.192 * * * \\
(0.0408)\end{array}$ & $\begin{array}{c}0.195 * * * \\
(0.0410)\end{array}$ & $\begin{array}{c}0.194 * * * \\
(0.0409)\end{array}$ & $\begin{array}{c}0.195 * * * \\
(0.0410)\end{array}$ \\
\hline Pop. municipality (log) & $\begin{array}{c}-0.0235 * * * \\
(0.00712)\end{array}$ & $\begin{array}{c}-0.0203 * * * \\
(0.00718)\end{array}$ & $\begin{array}{c}-0.0200 * * * \\
(0.00745)\end{array}$ & $\begin{array}{c}-0.0217 * * * \\
(0.00723)\end{array}$ & $\begin{array}{c}-0.0206 * * * \\
(0.00720)\end{array}$ & $\begin{array}{c}-0.0209 * * * \\
(0.00721)\end{array}$ \\
\hline COVID-19 & & $\begin{array}{c}0.733 * * * \\
(0.0562)\end{array}$ & $\begin{array}{c}0.734 * * * \\
(0.0570)\end{array}$ & $\begin{array}{c}0.748 * * * \\
(0.0531)\end{array}$ & $\begin{array}{c}0.741 * * * \\
(0.0544)\end{array}$ & $\begin{array}{c}0.744 * * * \\
(0.0537)\end{array}$ \\
\hline No lockdown & & $\begin{array}{l}-0.123 * * \\
(0.0551)\end{array}$ & $\begin{array}{l}-0.123 * * \\
(0.0549)\end{array}$ & $\begin{array}{l}-0.122 * * \\
(0.0540)\end{array}$ & $\begin{array}{l}-0.123 * * \\
(0.0542)\end{array}$ & $\begin{array}{l}-0.122 * * \\
(0.0543)\end{array}$ \\
\hline \# COVID-19 cases (county) & & & $\begin{array}{l}-4.18 \mathrm{e}-07 \\
(2.46 \mathrm{e}-06)\end{array}$ & & & \\
\hline$\%$ COVID-19 cases pop. county & & & & $\begin{array}{l}-7.638 \\
(4.297)\end{array}$ & & \\
\hline \# COVID-19 deaths (region) & & & & & $\begin{array}{l}-3.24 \mathrm{e}-06 \\
(2.60 \mathrm{e}-06)\end{array}$ & \\
\hline$\%$ COVID-19 deaths pop region & & & & & & $\begin{array}{l}-40.10 \\
(26.51)\end{array}$ \\
\hline Constant & $\begin{array}{c}2.199 * * * \\
(0.0872)\end{array}$ & $\begin{array}{c}2.054 * * * \\
(0.0904)\end{array}$ & $\begin{array}{c}2.052 * * * \\
(0.0910)\end{array}$ & $\begin{array}{c}2.095 * * * \\
(0.0931)\end{array}$ & $\begin{array}{c}2.067 * * * \\
(0.0909)\end{array}$ & $\begin{array}{c}2.080 * * * \\
(0.0920)\end{array}$ \\
\hline Observations & 6,692 & 6,643 & 6,643 & 6,643 & 6,643 & 6,643 \\
\hline
\end{tabular}

$417{ }^{(*)}$ Note: The estimates in the table refer to Poisson count models with double censoring (left at 0 , right at 26), sample weights and 418 robust standard errors. The dependent variable is the SMFQ score. For each variable, the coefficient, the standard error (in 419 parentheses), and the level of significance are reported as follows: *** significant at 99\%; ** significant at $95 \%$. 
Table 6: Result of econometric models on the (S)MFQ score: young adults vs. adults

\begin{tabular}{|c|c|c|c|}
\hline VARIABLES & $\begin{array}{c}(1) \\
\text { ALL } \\
\mathrm{mfq}\end{array}$ & $\begin{array}{c}(2) \\
16-24 \\
\mathrm{mfq} \\
\end{array}$ & $\begin{array}{c}(3) \\
25+ \\
\mathrm{mfq}\end{array}$ \\
\hline Gender (female) & $\begin{array}{c}0.238 * * * \\
(0.0302)\end{array}$ & $\begin{array}{c}0.267 * * * \\
(0.0791)\end{array}$ & $\begin{array}{c}0.241 * * * \\
(0.0328)\end{array}$ \\
\hline Age & $\begin{array}{c}-0.00985 * * * \\
(0.000838)\end{array}$ & $\begin{array}{c}0.101 * * * \\
(0.0143)\end{array}$ & $\begin{array}{c}-0.00954 * * * \\
(0.00113)\end{array}$ \\
\hline Unemployed & $\begin{array}{c}0.133 * * * \\
(0.0503)\end{array}$ & & $\begin{array}{l}0.125 * * \\
(0.0565)\end{array}$ \\
\hline Lay-off & $\begin{array}{c}0.316 * * * \\
(0.0802)\end{array}$ & & $\begin{array}{c}0.338 * * * \\
(0.0933)\end{array}$ \\
\hline Poor & $\begin{array}{c}0.219 * * * \\
(0.0425)\end{array}$ & $\begin{array}{c}0.143 \\
(0.187)\end{array}$ & $\begin{array}{c}0.227 * * * \\
(0.0458)\end{array}$ \\
\hline Living alone & $\begin{array}{c}0.192 * * * \\
(0.0409)\end{array}$ & & $\begin{array}{c}0.192 * * * \\
(0.0432)\end{array}$ \\
\hline Pop. municipality (log) & $\begin{array}{c}-0.0203 * * * \\
(0.00718)\end{array}$ & $\begin{array}{l}-0.0191 \\
(0.0193)\end{array}$ & $\begin{array}{l}-0.0188 * * \\
(0.00788)\end{array}$ \\
\hline COVID-19 & $\begin{array}{c}0.733 * * * \\
(0.0562)\end{array}$ & $\begin{array}{c}0.485^{* * * *} \\
(0.0870)\end{array}$ & $\begin{array}{c}0.770 * * * \\
(0.0619)\end{array}$ \\
\hline No lockdown & $\begin{array}{l}-0.123 * * \\
(0.0551)\end{array}$ & & $\begin{array}{l}-0.113 * * \\
(0.0565)\end{array}$ \\
\hline Constant & $\begin{array}{c}2.054 * * * \\
(0.0904)\end{array}$ & $\begin{array}{l}-0.147 \\
(0.361)\end{array}$ & $\begin{array}{c}2.008 * * * \\
(0.107)\end{array}$ \\
\hline Observations & 6,643 & 661 & 5,982 \\
\hline
\end{tabular}

${ }^{(*)}$ Note: The estimates in the table refer to Poisson count models with double censoring (left at 0 , right at 26), sample weights and robust standard errors. The dependent variable is the SMFQ score. For each variable, the coefficient, the standard error (in parentheses), and the level of significance are reported as follows: $* * *$ significant at $99 \%$; ** significant at $95 \%$. 
Figure 1: Distribution of (S)MFQ Scores on total population

431

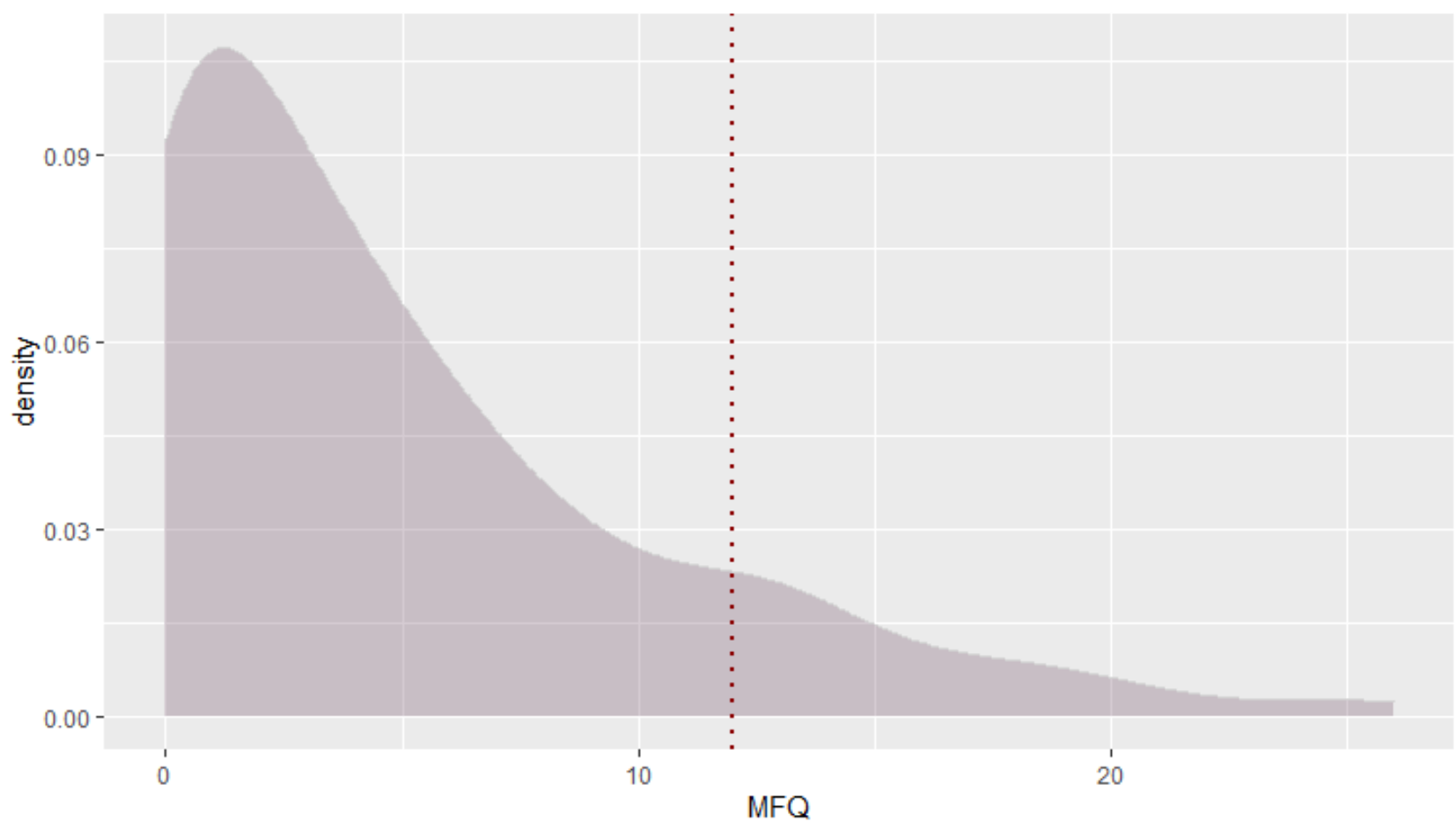

432

Figure 2: Distribution of (S)MFQ Scores on young adult (16-24) and adult (25+) groups

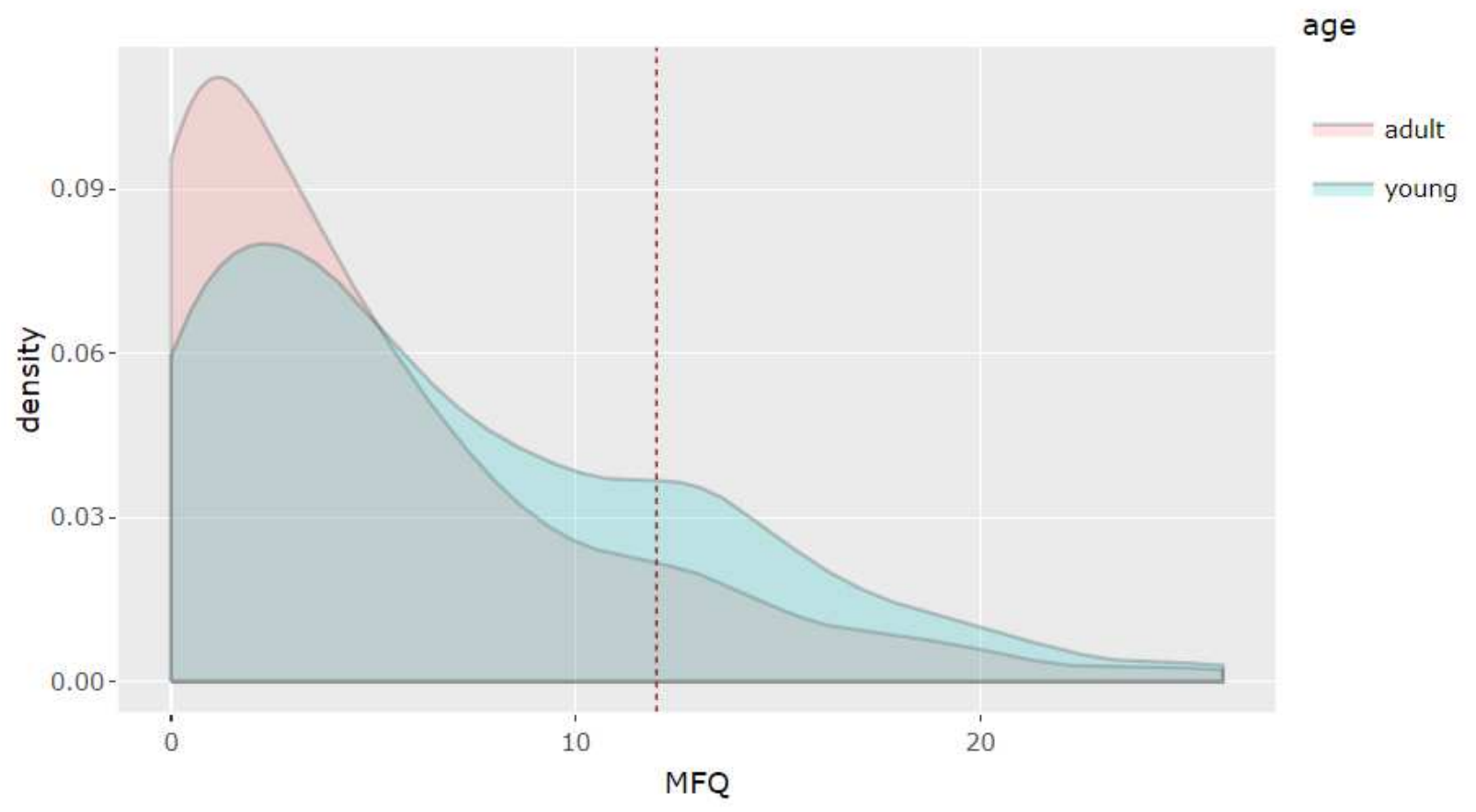


$100 \%$
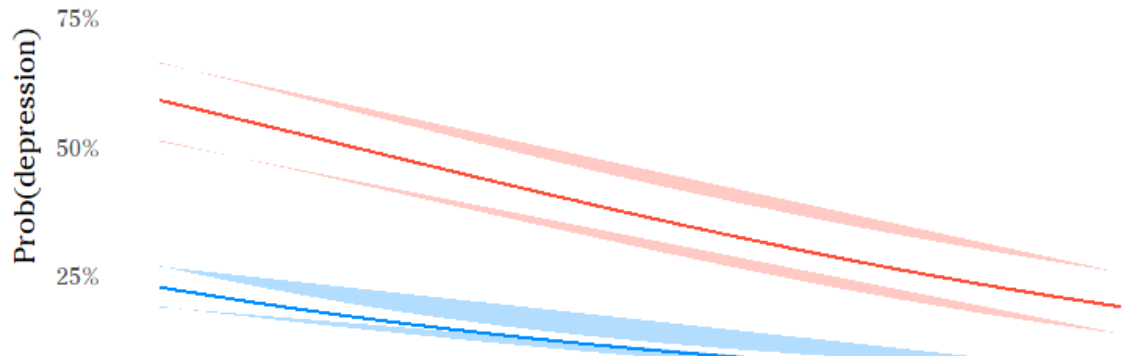

$0 \%$

${ }^{(*)}$ Note: effects calculated on the basis of the probit model of Table A.2 (age interval: 16-95). Confidence interval at $99 \%$.

Figure 3b: The effect of lockdown on the probability of depression (cut-off $\geq 12$ )

$$
\text { Lockdown - No Lockdown }
$$

$100 \%$

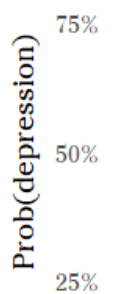

$0 \%$ 
Figures

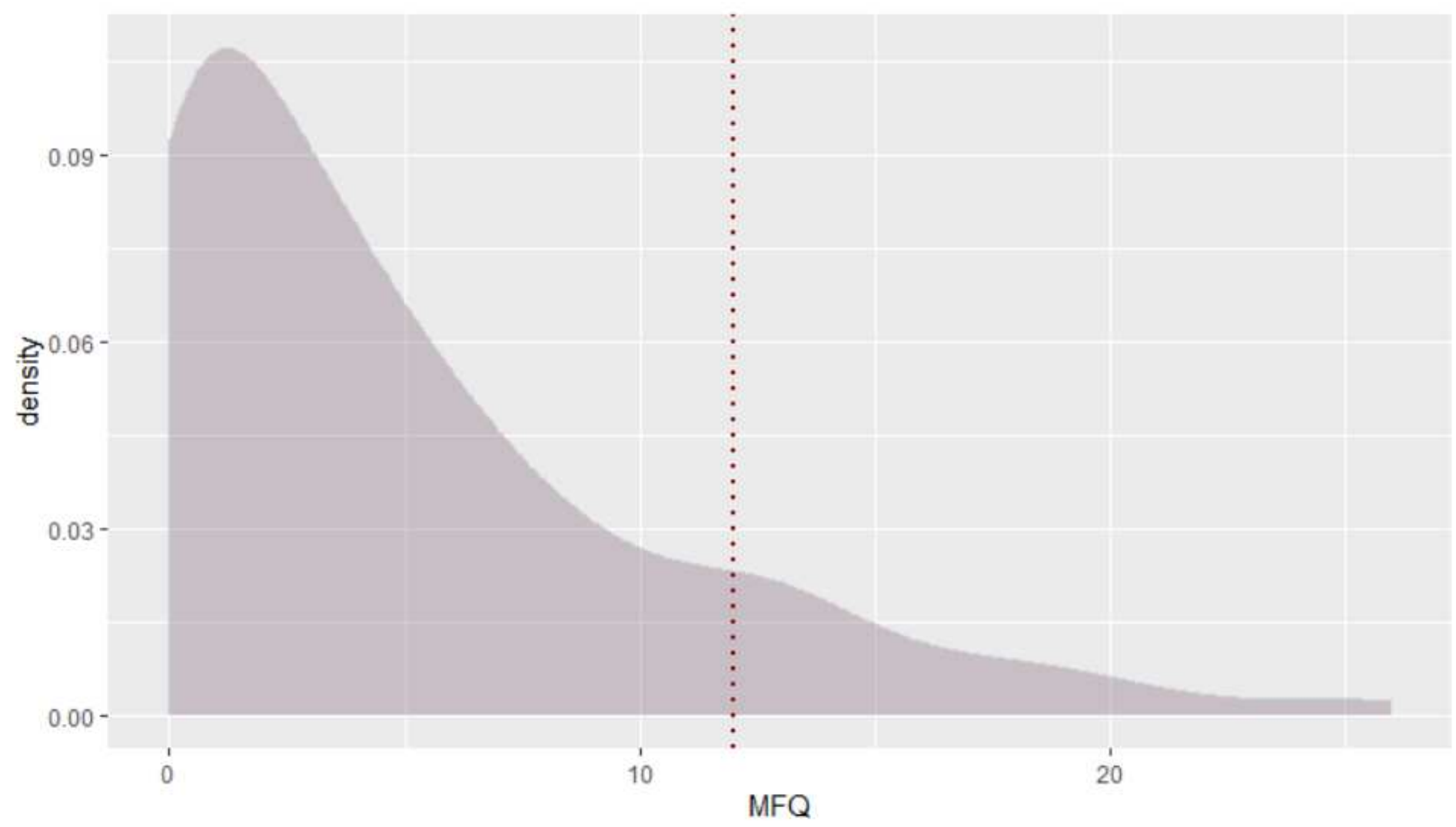

Figure 1

Distribution of (S)MFQ Scores on total population 


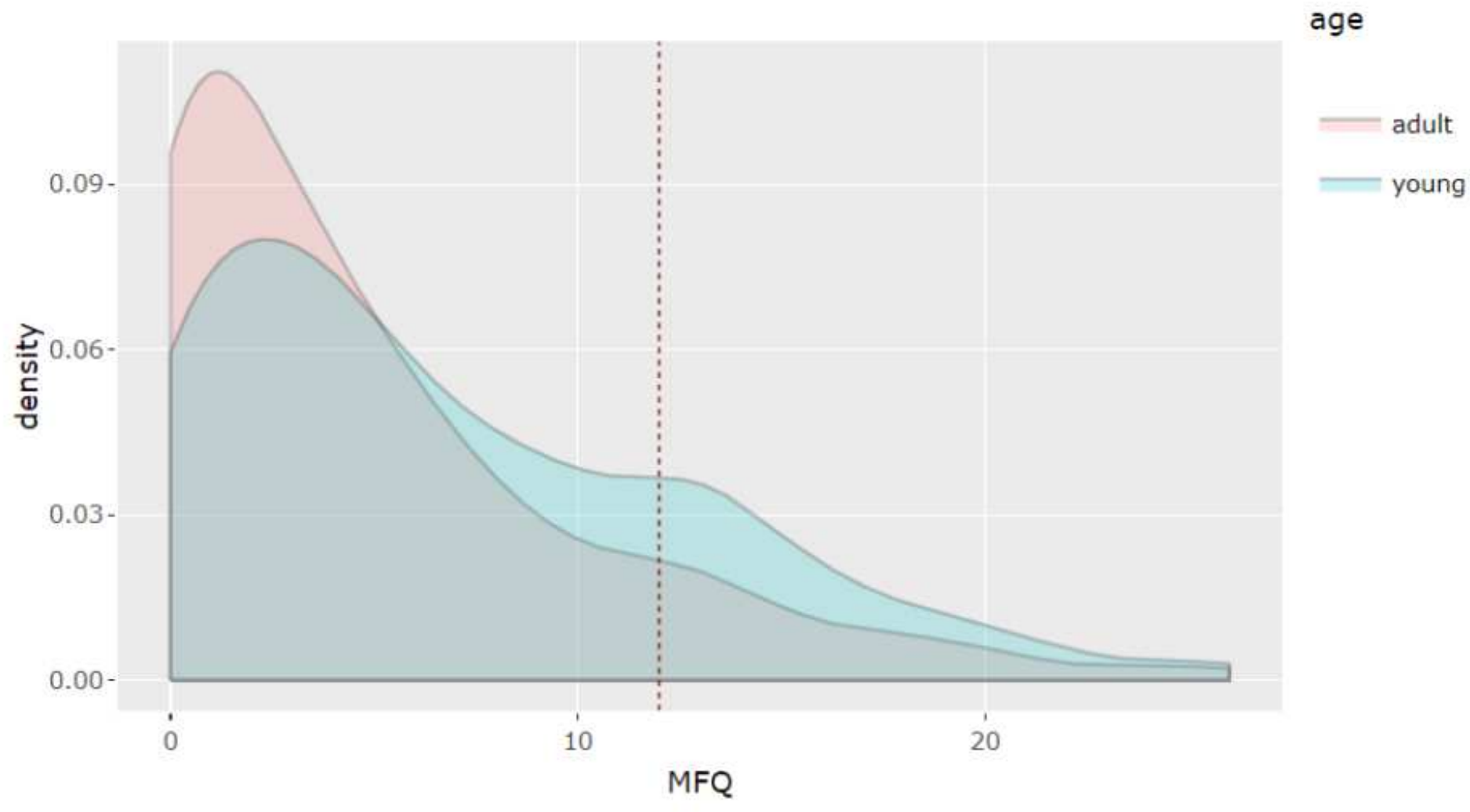

Figure 2

Distribution of (S)MFQ Scores on young adult (16-24) and adult (25+) groups 
Figure 3a: The effect of COVID-19 on the probability of depression (cut-off $\geq 12$ )

Covid-19 $=$ No Covid-19

$100 \%$
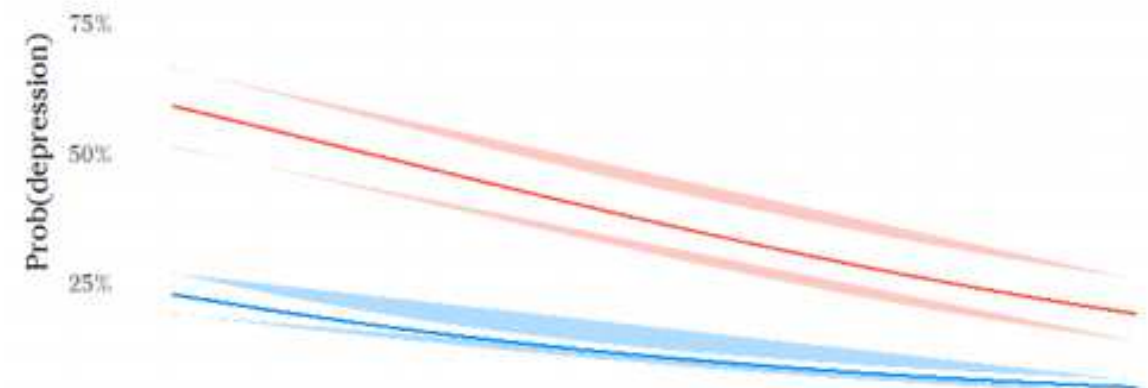

$0 \%$

25

50 Age

75

(9 Note: effects calculated on the basis of the probit model of Table A.2 (age interval: 16-95). Confidence interval at $99 \%$.

Figure 3b: The effect of lockdown on the probability of depression (cut-off $\geq 12$ )

Lockdown - No Lockdown

$100 \%$

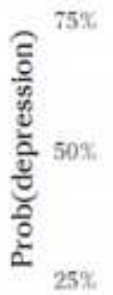

$0 \%$

$30 \quad$ Age $50 \quad 60$

(") Note: effects calculated on the basis of the probit model of Table A.2 (age interval: 25-65). Confidence interval at $99 \%$.

\section{Figure 3}

a: The effect of COVID-19 on the probability of depression (cut-off $\geq 12$ ). b: The effect of lockdown on the probability of depression (cut-off $\geq 12$ )

\section{Supplementary Files}


This is a list of supplementary files associated with this preprint. Click to download.

- SupplementaryfileDelmastroZamariolaSR.pdf 